\title{
"If you could change two things": Social workers in schools talk about what could improve schools' responses to child abuse and neglect
}

Liz Beddoe, Irene de Haan and Eileen Joy University of Auckland, New Zealand

\begin{abstract}
INTRODUCTION: Given recent legislative changes to the child welfare system in Aotearoa New Zealand, it was deemed timely to examine the challenges faced by school-based social workers and other school professionals in responding to child abuse and neglect (CAN).

METHOD: A qualitative study of school professionals' responses to CAN included 20 semistructured interviews with school-based social workers. The participants were asked to describe two things that, from their perspective, would improve schools' responses to CAN. This article reports on this aspect of the study.

FINDINGS: Four main themes were identified in social workers' responses: the necessity for improved training for teachers on CAN; better support for teachers; a more holistic approach to child wellbeing; and enhanced understanding of child welfare.

IMPLICATIONS: These findings pose challenges to both initial teacher education and crossagency child protection. School social workers use their relationship skills and knowledge to act as bridges between teacher education, school leaders, teachers and the Ministry for Children Oranga Tamariki and believe they can do more.
\end{abstract}

KEYWORDS: social workers in schools; child abuse and neglect
Thirty years have passed since the initial pilot of the "social workers in schools" (SWiS) programme and, given the proposed legislative and impending structural changes to the contracting body, and child protection in general in Aotearoa New Zealand, it is worth examining both the nature of the work and the experiences of school social workers. New legislation in 2014 (the Vulnerable Children Act) positioned teachers, along with other professionals in the children's workforce, as significant in a collaborative response to CAN. This legislation has generated a wider emphasis on an expanded group of professionals and organisations, including teachers and schools, to take a role in noticing and responding to child abuse and neglect. Social work is a core part of that effort in schools which have social work input as part of their pastoral care provision.

This article reports on findings from interviews with 20 school social workers and focuses specifically on their responses to a question about how schools' responses to children in need might improve. A brief
AOTEAROA

NEW ZEALAND SOCIAL WORK 30(1), 45-57.

CORRESPONDENCE TO: Liz Beddoe

e.beddoe@auckland.ac.nz 
overview of school social work in Aotearoa New Zealand is provided first, followed by a consideration of some themes emerging from the international literature.

After a successful pilot in 1999, school social work in Aotearoa New Zealand was launched as a government-funded service in selected schools (Ministry of Social Development [MSD], n.d.a). The programme is currently managed by the state child protection agency, Oranga Tamariki - Ministry for Children, and has had successive increases in funding and scope over the last 20 years. The services themselves are managed and run by social service organisations, including iwi, churchbased and non-government providers, who contract to the MSD. The programme is geared towards provision within schools in lower socioeconomic areas and "recognises the special needs of Māori and Pacific children and families within these schools" (MSD, n.d.a). It is important to note that the provision of such services is also based on student numbers, and one social worker might be required to work across a few different schools rather than being based in one - thus SWiS workers may find themselves working within several different communities. Some school-based social workers are employed under contracts with other organisations.

The programme was set up recognising that "schools are sites for social work interventions because they provide a non-threatening point of access for most families" (Belgrave et al., 2002, p. $8)$. Internationally, it is recognised that schools, particularly primary schools, are like a second home for children, and that, given school staff, after families, generally have the most contact with children, they are ideally placed to monitor children's behaviour and any changes that might indicate child maltreatment and neglect (Buckley \& McGarry, 2011; Scannapieco, 2006). More importantly, it has been recognised that, although schools' main focus is academic, it would be foolish to ignore the impacts other environmental influences have on the ability of a child to learn (Scannapieco, 2006). Whilst the SWiS programme was not set up with the exclusive aim of helping detect and prevent CAN, referral and support for families where abuse and neglect may be occurring is one of the core roles for SWiS workers (Belgrave et al., 2002). The SWiS role also involves helping children and their families manage financial difficulties, address grief and loss, family violence and behavioural challenges. In summary, the role encompasses anything that could impact on a child's learning and emotional wellbeing where the support of social services is needed (Ministry of Social Development, n.d.b).

Given the political volatility and breakouts of politically generated moral panic over child abuse in Aotearoa New Zealand and other countries (Beddoe, 2015), an examination of schools' activity in this regard is timely. School-based social workers engage with various stakeholders - parents, children, principals and schools, contract providers, the community and statutory agencies- in response to CAN concerns. In the present study we have explored SWiS' perceptions of school professionals' (principals, teachers and, sometimes, health or specialist staff) recognition of and response to CAN within their schools. We were interested to find out how SWiS manage relationships within the school to achieve positive outcomes for children experiencing maltreatment and neglect. This latter focus is particularly relevant given SWiS operate in a space between school and welfare systems and are often isolated in their work (Beddoe, 2017). They are not teachers, yet are expected to operate in an environment which essentially has different motivations and aims to social work (Isaksson \& Sjöström, 2016; Phillippo \& Blosser, 2013; Sherman, 2016). While research has been conducted on school social work in Aotearoa New Zealand, it is also important to examine international research in order to explore what themes might be local and those 
which may resonate with school-based social work elsewhere.

Our findings identify improvements that can be made to school responses to child abuse and neglect and pose challenges to both initial teacher education and child protection agencies to ensure that teachers have good information about CAN and are supported to work proactively. We argue that SWiS identify the need for more education for teachers and greater support for their role in strengthening the bridge between teacher education, school leaders and the new statutory agency, the Ministry for Children Oranga Tamariki.

\section{LITERATURE REVIEW}

\section{School social work in Aotearoa New Zealand}

As already mentioned, social work in schools in Aotearoa New Zealand has a relatively short history. To date research data has been generated from the programme evaluation work carried out for government (Belgrave, 2000; Belgrave et al., 2002), and an examination of the role of Māori school social workers within the system (Hollis-English \& Selby, 2014; Selby, English, \& Bell, 2011). As a consequence, there has yet to be a detailed examination of many of the issues that have been comprehensively covered by researchers in countries where school social work has a far longer history. A brief review of local and international literature identifies challenges, some of which are specific to the Aotearoa New Zealand situation where SWiS are employed by social service agencies, not schools.

It was noted that, in creating the SWiS programme, different models of "employment" were considered. Crucial to the programme was the fact that school was viewed as "a site for social work intervention" (Belgrave, 2000, p. 10) which stands in contrast to the US where school social workers are seen as working for schools rather than independently working for children and families. SWiS are expected to work alongside schools, as an intervention and detection service, but the primary client is the child. School social workers might be less able to act as mediators between the school and the child when the school is the employer.

A set of specific programme issues were reported in the evaluation "Social workers in schools: Expansion evaluation" (Belgrave et al., 2002):

- $\quad$ There was confusion about the SWiS role, where some managerial tasks, meant to be undertaken by the contract holders were left for SWiS to do, creating workload pressure.

- $\quad$ Principals were found to be gatekeeping referrals assuming that some issues were too trivial for the SWiS worker. However, a higher level of trust made it more comfortable for principals to leave it to the SWiS worker to assess referral appropriateness. It was noted that the danger in this gatekeeping is that education staff were not specifically trained in social work assessments and might miss crucial information.

- Most schools found that the presence of a SWiS freed up education staff to concentrate on other areas rather than spending time meeting with social service providers.

- Key strengths of the programme were identified as the voluntary nature of involvement for families, the independence of social workers, and their ability to access a wide range of resources.

The expanded Aotearoa New Zealand programme includes a strong presence of iwi providers with input from Māori practitioners. This has meant that a Mãori worldview has been incorporated into many SWiS programmes, although not all, and the strengths offered may produce different experiences than those of social workers in other countries (Hollis-English \& Selby, 2011). 
In a discussion of the SWiS programme from the point of view of the Mãori school social workers, Hollis-English and Selby (2014) and Selby et al. (2011), have noted that because SWiS were community-based, they were both accountable to and supported by the elders of the area. This was part of creating kaupapa Māori practice - best practice for working with Māori - embracing and re-centring "interdependence with one's extended family" (Hollis-English \& Selby, 2014, p. 8).

\section{Two professions - challenges of working with teachers on child welfare concerns}

In the international literature, aspects of relationships between social workers and teachers and principals feature prominently. Individual practitioners often feel caught between two professions and, due to their relative isolation from social work peers, may feel marginalised within the school environment (Sherman, 2016). There were many challenges mentioned in the literature about these relationships and a brief overview of research follows.

A frequent theme in the literature is that teachers often misunderstand social work (Altshuler \& Webb, 2009; Belgrave, 2000; Belgrave et al., 2002; Corbin, 2005; Dupper, 2003; Minnich, 2014; Peckover, Vasquez, Van Housen, Saunders, \& Allen, 2012; Poppy, 2012). There is role ambiguity, and in response, school social workers are advised to spend more time advocating for themselves to education staff (Garrett, 2006; Goren, 2006) and offering staff education (Allen-Meares, 1994; Minnich, 2014; Phillippo \& Blosser, 2013) in order to reduce misunderstanding. Role ambiguity is thought to feed into role diffusion and confusion about what school social workers do (Altshuler \& Webb, 2009; Poppy, 2012). Misunderstanding of the social work role and contributions can result in a lack of respect from educational staff, particularly when compared to other non-teaching professionals such as counsellors and psychologists (Altshuler \& Webb, 2009; Dupper, 2003).

As a corollary to the theme addressed above, it is often noted that school social workers, in order to build relationships with other school professionals, must spend time learning about the education system and the specific bureaucracy it uses (Beddoe, 2017; Jarolmen, 2014; Kelly, Frey, \& Anderson-Butcher, 2010; Pawlak \& Cousins, 2006; Poppy, 2012). While this is felt to be a proactive positive move it may also be a defensive strategy to ensure school social workers do not "alienat[e] the very system of which they are a part" (Staudt \& Kemp Powell, 1996, p. 442).

The literature also reports a lack of agreement about the social work role. While there is considerable agreement about what sort of tasks school social workers should be doing, there are significantly discrepant areas between them and senior school administrators. Differences have been noted about what constituted reporting (social workers rated informal conversations as an example of this but administrators did not), and the desirable level of parental involvement (Bye, Shepard, Partridge, \& Alvarez, 2009). As the authors have noted elsewhere (Beddoe \& De Haan, 2018), in New Zealand considerable variation in the role of making formal notifications of concerns has been reported. In some schools, SWiS made all the notifications, in others, none, while others were inconsistent in their processes. Inevitably, perhaps in the fraught territory of reporting concerns, agreement may be difficult to achieve. Factors which may impact are heightened emotions about child abuse and, significantly, differences in CAN reporting thresholds (Levi, Crowell, Walsh, \& Dellasega, 2015; Levi \& Portwood, 2011).

The prevalence of child maltreatment is often hard to measure due to the hidden nature of occurrences and confusion around what actually "counts" as CAN in the eyes of the potential reporter. Researchers have noted that definitions can be difficult to apply and 
can cause doubt and confusion to anyone detecting and reporting (Daniel, Taylor, \& Scott, 2010; Levi \& Portwood, 2011; O'Toole, Webster, O'Toole, \& Lucal, 1999; Schols, de Ruiter, \& Ory, 2013). Further, with regard to neglect, a "narrowing in definitions [occurs] the closer the child comes to professionals" (Daniel et al., 2010, p. 252). In practice, this may mean that a layperson may define abuse and neglect more broadly than does a teacher, whose definition is wider than a non-statutory family violence agency, whose definition will be broader than a statutory agency. These definitional concerns may provide the conditions for frustration felt by teachers when statutory child protection does not act on their concerns. As a consequence, discussion with school professionals about reporting thresholds is important for school social workers when a clear protocol is not in place.

Social workers frequently describe teachers as often only seeing the academic side of children, rather than seeing the child positioned within their kinship group and community (Hollis-English \& Selby, 2014; Minnich, 2014; Peckover et al., 2012; Whittlesey-Jerome, 2013). The absence of an ecological model (Ungar, 2002) results in a "deficit view" that "reduces the social complexity of problems" (Isaksson \& Sjöström, 2016, p. 8). School professionals may become focused on "quick fixes" in the complex family problems that social workers address. Small gains, made via longer term changes, often school-wide or even community-wide and individual change in family systems, may not be recognised (Altshuler \& Webb, 2009; Isaksson \& Sjöström, 2016). Relationships with families are crucial from a change-oriented ecological social work perspective. In a US study, school social workers believed that liaising with parents was a much more fundamental part of their role than liaising with school staff (Kurtz \& Barth, 1989). A decade later, Bye et al. (2009) found that $83 \%$ of the school social workers surveyed wanted increased parental involvement in their cases, while only $50 \%$ of administrators wanted parents more involved in school social work. This then perhaps speaks to the differing professional frameworks - for social workers, keeping wider eco-systems clearly in view is crucial, for teachers, this emphasis is not as critical.

Recent focus on the teacher's role in child protection is predicated on their close daily contact with children and abilty to identify changes in children's physical and psychological wellbeing (Buckley \& McGarry, 2011). This is especially true for the teachers of New Zealand primary school children (aged 5-12), where it is the norm for a child to spend the majority of their time with one dedicated teacher, or in the case of the newer collaborative classrooms, two teachers. Child abuse and neglect can have a significant impact on a child's ability to fully participate in primary school life with the ramifications of undetected of unreported CAN might have ripple effects which can last years (Klika \& Herrenkohl, 2013; Romano, Babchishin, Marquis, \& Frechette, 2015). Researchers in this field have noted the critical role of teachers in detecting and reporting CAN. Accordingly, much research has been undertaken in Australia (Walsh, Mathews, Rassafiani, Farrell, \& Butler, 2012), the United States (O'Toole et al., 1999; Webster, O'Toole, O'Toole, \& Lucal, 2005), the United Kingdom (Baginsky \& Macpherson, 2005; McKee \& Dillenburger, 2010; Webb \& Vulliamy, 2001) and other countries (Buckley \& McGarry, 2011; McGarry \& Buckley, 2013; Schols et al., 2013). Aotearoa New Zealand research on professionals' reporting behaviour has however, been limited and the most recent data were collated by Rodriguez (2002) who reported that, in the absence of legislated mandatory reporting, teachers and other professionals make decisions about reporting child abuse concerns based on subjective judgment and knowledge of situational factors.

Against this backdrop of research, it is surprising that little is known about how social workers and school professionals work together to address matters of child welfare. This article reports on aspects of a sequential 
qualitative study, with a particular focus on school-based social workers and their beliefs about what needs to change to improve school processes of addressing child welfare concerns.

\section{METHOD}

A qualitative study comprising three phases over several years has been conducted, involving SWiS, (reported in this article), school principals and early career teachers (to be reported elsewhere). A qualitative approach was selected to allow investigation of under-researched school practice. The selected method of semi-structured interviews enables researchers to explore people's opinions and examine the underlying rationale for perceptions. The qualitative research process begins with "conscious and unconscious questions and assumptions that serve as a foundation for an epistemological position" (Nagy Hesse-Biber \& Leavy, 2004, p. 2). In this study, an assumption was that school-based social workers would have a unique perspective on the organisational context in which they act as bridges between education and welfare systems.

The study received ethical approval from the University of Auckland Human Participants Ethics committee. Social workers received an invitation to participate sent out by their main professional association, the Aotearoa New Zealand Association of Social Workers. The initial response was very swift and positive. All those offering to participate received an information sheet and consent form prior to the interview. Sixty social workers requested further information and 40 offered to be interviewed; however, not all returned the consent forms and of those who did, 20 were able to participate in an interview during the time available. Twenty semi-structured telephone or Skype interviews of between 30 and 90 minutes' duration were conducted. The questions were driven by the main research focus of the larger study, along with some questions designed to explore school-based social workers' particular experiences, and the challenges and opportunities afforded by their roles. Saturation was noted at 20 interviews, with clear, consistent narratives developing in the interviews.

Of the 20 interview participants, 11 identified as NZ European, five as Māori and four as other European. Fifteen were female and five were male. The age range was: $31-40$ $\mathrm{N}=4 ; 41-50 \mathrm{~N}=8 ; 51+\mathrm{N}=8$. All interview participants held social work qualifications and all were registered, 16 holding full registration while four new graduate participants held provisional registration. Efforts were made to recruit younger social workers and those from Pasifika ethnicities but these did not generate more interviews within the timeframe for data collection.

A significant aim of this part of the research was to understand what it was like to be a social worker in a school setting and to explore how professional dynamics might influence school responses to concerns about CAN. The interviews explored four broad topics: participants' perceptions of their readiness to work in a school environment and the knowledge and skills needed; the strengths and challenges of practising social work in a school setting (reported in Beddoe, 2017); the processes the participants' schools followed when concerns were raised about a child; and the social workers' beliefs about what they would like to change in how schools respond to CAN. The latter question was phrased as a kind of miracle question, as the first author has found such questions, borrowed from solution-focused therapy, to be useful in qualitative research as a means of eliciting future-oriented ideas and aspirations, freed from the constraints of now. Each participant was asked: "if you had power and resources and could how your schools respond, what would be the two things that you would like to change?"

The interviews were audio-recorded and transcribed. The interview data were coded using NVivo11 (QSR International). An initial coding augmented by text searches generated 50 nodes. Consecutive reading 
of node reports contributed to further understanding and reduction of the data as repetitive patterns were identified. These patterns, based on multiple participants describing very similar experiences were then collapsed into the themes outlined above. The findings reported here have been mainly drawn from answers to the question: "If you could change two things..." Pseudonyms are used for participant quotes. Potentially identifying information has been removed.

\section{FINDINGS}

The four most frequently coded themes identified in social workers' responses to this particular topic were: improved training on CAN for school staff; better support for teachers; a more holistic approach to child wellbeing; and improved understanding and relationship with the statutory child protection authority. It is to be noted that SWiS recognised the demands on classroom teachers and were sympathetic to the limits of their ability to respond to concerns.

\section{Improved child abuse training for school staff}

A consistent aspiration was that the whole school workforce would be well prepared and equipped to address concerns about CAN and that teachers would "see themselves as a key part in that process. Not the only part, but a key part in that process" (Sam). Chrissie wanted signs of child abuse and ways to respond to be a "mandatory part of their training, part of the schools" and for there to be policy and procedures in place that teachers were trained in. "Teachers' understanding the process of how to proceed with the next steps, where to from here" (Chrissie). A focus on training for teachers was echoed by others:

But if they actually had training around that, you know, this is what neglect looks like, you know, these are the signs, then they can be more confident in following the schools process of how to report. (Cindy)
Well, timeliness in terms of really being able to identify early, early signs of something not being right. (Debbie)

Yeah, and all teaching staff on the frontline and principals and teacher aides having first response child protection training. (John)

Jen expressed clearly a common concern that often teachers do not have CAN at the front of their minds: "They don't think about it and I don't know whether it is because they get used to it or yeah whether they don't know to look for the signs." Because of this concern, Jen really valued school staff working together with other professionals to ensure that a team approach might contribute to better understanding of a family, an example being:

...because the public health nurse has been called in by the school to have a look at a child who has got sores and haven't been healing... and I don't know about that and I'm working with them on some other issues, [say] parenting. Maybe I'm not even working with the child, I'm working with the parents, because that can often happen, you know. [Working together] actually paints a picture of what's going on, the problems that that family is experiencing. (Jen)

Teachers need training in CAN because, "you know, they're seeing kids every day and often have the most information out of any professional that's involved with them" (Patrick). Teachers need to understand child abuse and how it affects children and "the way schools and social workers hold hands and work together" to address it (Jackie).

Teachers being able to join the dots was vital in Jen's view as they are in a position to observe possible signs for concern over time:

...it is the things that underline it, they think about the child being absent from school, a few days a week, and, if this is a regular occurrence and if they are not 
wearing the appropriate clothing to school and if they don't brush their hair, or their skin looks..., or [she]becomes withdrawn, you know. There's all these little clues that can [signal] neglect. Often, they actually don't tie that all together. (Jen)

There was also a strong emphasis on training to ensure that processes were clear when concerns were noted and action was needed. There were two main elements to this, firstly making an appropriate first response, as also noted by John above, the second about clarity of role, an issue noted previously in literature. "So, everyone gets each other's role and how to collaborate" (John).

Jessica wanted to see a common understanding of how to address concerns: "But ... it's not going in like a bull in a china shop. There's still got to be a level of respect with all families that we work with no matter what is happening." She recognised this was difficult work: "it's the hardest thing to sit across from someone that has sexually abused a child and let them know what you are going to do without going 'how could you do this,' you know, you can't" (Jessica).

Elsie wanted teachers to have refresher training each year on the signs of abuse:

...the teachers that sometimes need it the most are the teachers that have been there the longest. Sometimes they're the ones the most reluctant.... The newer ones coming in are more open to the learning, this is just my impression, is they are open to the learning but they actually know a lot as well. They see the confidence building. (Elsie)

Many of the participants' apprehensions were about mis-understanding of how social workers practice when dealing with CAN and the potential for unrealistic expectations of the child welfare system. It was important for school professionals to understand there is insufficient capacity to provide instant responses, "you know, there's not enough people. So, I would change that first."
(Jessica). To counter this, John wanted every school to have a social worker regardless of decile (school socioeconomic rating):

...because you know...smaller schools get half a social worker [on a head count basis]. So, what you've got of course is decile 1 school with small rolls being absolutely full of issues. (John)

Sorting out responsibilities and processes for notifications to the then-named Child, Youth and Family service (CYF) was vital to ensure consistent approaches: "I think often it is there are not any really clear processes and maybe it is just down to teachers not knowing what the processes are" (Patrick).

\section{Better support for teachers}

The school social workers were unanimous that teachers needed more support. They were very clear that teachers' roles were pivotal, as expressed clearly by Sam:

Because when I talk to children, at times teachers are a key people within their life, key people and when I talk to older people and they reflect on what was it that helped them achieve the level that they achieved most of them go back to one or two other people as well, but [at least] one or two teachers that were absolutely in their corner. (Sam)

There was strong support for SWiS having more time to support and work with classroom teachers and to offer consultation about children where the teacher held concerns. Elsie argued that if she was in charge she "would have a trained social worker that they can consult with if they were concerned. I think just providing that level of support for them would help alleviate anxiety that they may take home with them" (Elsie). A social worker might even cover 10 schools but could be available to be contacted by any school to run through anything in terms of: "I'm worried about this child because I don't know if there is something going on can you come in and have a chat with them." 
Comments were made about levels of support for teachers to manage concerns, especially when one classroom might have several children of significant concern. Reduction of class sizes and the employment of more trained ancillary staff to ensure support of students in a variety of different ways and more opportunity for observation. Stuart saw very stressed teachers and on his "wishlist" were the following:

...more emotional support for staff... more opportunities to have time out of the classroom to talk to other professionals. I know that the teachers at some of the schools I've worked in... if they had more time they would spend more time having these conversations with myself or with the guidance counsellor or the school nurse. (Stuart)

Linda felt that teachers needed time to think about their observations when alarmed by what they see and needed to feel ok to communicate with the principal and have "time out from their classroom even to process it...to have debriefs. That is some of the stuff that doesn't happen because they are so busy and schools are such structured places and I think teachers get stressed about kids" (Linda).

Like Stuart earlier, Linda thought SWiS workloads and splits across schools meant that they did not have time to do all they could to support teachers. Linda argued that SWiS had a great deal to contribute to the school environment:

...creating environments and creating systems and having that advisory role consultancy role with school staff. That sometimes happens on the hop on the run and yeah particularly if you are hopping between schools, yeah. A whole lot more value could be added to those roles. (Linda)

\section{A more holistic approach to children}

Echoing the international literature, the SWiS participants interviewed wanted the culture and resources to ensure a holistic approach to child welfare in their schools, offering ideas about how a child-centred approach would ensure better outcomes. For example, Sam noted that, from a child's perspective where abuse was confirmed and they needed to be removed, it might be very important that they could maintain a relationship with their school in some way. Timely and comprehensive processes to address child abuse and encompass the whole situation and support to make things better for children would also impact on their academic learning. Marie commented on the importance of wraparound support:

Because sometimes I feel that things are still being a little bit too separate as well as educational or social whereas if you work on the one thing the other thing will improve as well. So that whole wraparound idea of helping and supporting children and families from all different angles.

Marie was from a European country and noticed that practice in Aotearoa New Zealand "is still moving towards being child-focused and I think that having a social worker in school definitely contributes to that [ideal].". Advocacy for a more holistic and child-centred approach was a "very, very positive thing and as a social worker in schools I think you be very child focused in your work... and give children a stronger voice now and then" (Marie).

For Jessica, a critical issue was understanding and respect for tikanga and kaupapa and seeing the child also within their wider cultural context. Alison recognised that she adapted her assessment tools depending on the nature of the school:

Being Māori I naturally came with assessment tools that sort of looked holistically at the tamariki and to adapt those to suit Catholic schools, to suit kaupapa Māori [and] to suit mainstream, where there were perhaps more predominantly Pacific Island or Middle Eastern children. 
Linda wanted teachers to move beyond just seeing children as 'an emotional being, a learning being, and a social being' to seeing that they are also part of whānau, hapū and iwi: "they are not seeing the spiritual dimensions of that child and teachers tend to work from that, you know, that cup half full half empty thing rather than the cup being full."

\section{Improved relationships with statutory child protection}

SWiS expressed concerns about teachers' and schools' attitudes towards statutory services and were unanimous that they could, and did, offer their skills to improving relationships. Chrissie felt that she needed to be an advocate for CYF social workers because she observed a lack of understanding around the limitations of the legislation that statutory social workers work within. Debbie also felt that this advocacy was a big part of the SWiS role: "advocacy for children, and that often puts you in a kind of adversarial position within the school" (Debbie). These dynamics led to an $u s$ and them approach to statutory social work, with school professionals becoming protective towards the family and believing that they could solve the problems themselves:

[It is important] that the schools are not overly protective... because there are some things that just need to go to CYF and you can't fix it. The principal can't, you know...fix that issue and I've seen that many a time that staff and the school end up taking on the family, the families are raruraru ${ }^{i}$ and it doesn't sit with schools, it needs to sit with the right professions. (Alison)

Most participants believed that there needs to be closer communication systems developing between the local child protection office and schools.

Participants believed it to be vital that school professionals understood the significant differences between what statutory social workers and SWiS can do in child protection. Reports of concern processes and outcomes were sometimes a source of conflict (reported in more detail in Beddoe and de Haan, 2018).

The lack of effective communications was a significant issue, SWiS having relationships with both systems, often heard about the problems, as this could be two-way critique:

Yeah, I think there's a real frustration between, you know, lack of communication. And I did notice when I worked at CYF there were some schools that were great at welcoming you and other schools were like it doesn't happen in our school. You are not made to feel welcome, you know. (Kate)

Better communication between a local CYF office and the school and the provision of training about statutory processes might reduce the potential for misunderstandings about timeframes and practices:

[When it is a] critical seven days, a '14 days' and when it's children under five you've got so many days to make a decision, you know. So, this is maybe why you don't hear back. I think, you know, I just think there is a big gap there that is not helping. (Kate)

Finally, there were clearly expressed aspirations for improved pastoral resources for schools: with Allison saying, "if I could change two things one would be to include a SWiS or a social worker in the process" of addressing all CAN concerns. Teacher aides were recognised as doing "the hardest job" and they needed to work with SWiS to liaise with "usually pretty tricky families" and the child and teachers: "I think I'm not sure we are valuing that position enough" (Jack). Jack called for much greater integration of efforts for children at risk:

I would look at writing some form of alternative education within the primary school sector...I think schools and teachers probably need to be allowed to 
be more flexible to respond to the needs in their school.

\section{DISCUSSION AND CONCLUSIONS}

The article reports on phase one of a qualitative study which has explored the role of schools in responding to child maltreatment. School-based social workers have reported that they hold a key role, working closely with school principals, in responding to potential CAN. The findings are well aligned to the themes from the literature cited earlier. There is considerable agreement with earlier research, especially in relation to reporting processes (Rodriguez, 2002); the contributions of and regard for social work (Altshuler \& Webb, 2009; Belgrave et al., 2002; Dupper, 2003; Minnich, 2014), and the importance of a holistic perspective of the positioning of children within kinship and community (HollisEnglish \& Selby, 2014; Selby et al., 2011).

In particular, participants in the study confirmed the need for greater role clarity about the different parts that school professionals, statutory services and school-based social workers play in child welfare, suggesting that some long-standing troublesome elements of the programme remain. Many of the issues identified by Belgrave et al. (2002) and summarised earlier in this article remain unresolved. Misunderstanding of professional roles and limits to power, concerns about quick fixes, a lack of a holistic view of children, as members of whānau and community featured in the earlier discussion. Of greatest significance was the desire to see much improved communication between schools and statutory social services, with a focus on reducing the potential for frustrations and misunderstandings. Social workers were conscious of their bridging roles between systems, necessitated by the emotional politics and anxieties associated with child abuse and child protection (Warner, 2015).

Teachers' need for education and support was a significant theme. School-based social workers were largely very sympathetic to the challenges faced by teachers and recognised the stresses in the education system and felt they had a great deal to offer if better resourced. Critically, improved understanding and relationships between schools and statutory services might lead to more effective response, and consequently impact on how efficacious a school social worker feels in fulfilling their obligations.

This is an exploratory study and reflects only the perceptions of the social workers interviewed. We note the absence of Pasifika perspectives and future research would need to take steps to include Pasifika voices. The views of school principals and teachers are being sought in another phase of the study. These findings do, however, pose challenges to both initial teacher education and statutory child protection to ensure that teachers have sufficient knowledge about CAN to act when needed. The respectful concern expressed by the SWiS participants suggest that teachers do need opportunities to discuss their concerns and fears with knowledgeable and supportive social workers. The SWiS programme has considerable capacity to further empower social workers to act as bridges between ITE, school leaders, teachers and statutory child protection.

Funding: This study received funding from the University of Auckland Faculty of Education and Social Work Research Development Fund.

\section{References}

Allen-Meares, P. (1994). Social work services in schools: A national study of entry-level tasks. Social Work, 39(5), 560-565.

Altshuler, S. J., \& Webb, J. R. (2009). School social work: Increasing the legitimacy of the profession. Children \& Schools, 31(4), 207-218.

Baginsky, M., \& Macpherson, P. (2005). Training teachers to safeguard children: Developing a consistent approach. Child Abuse Review, 14(5), 317-330.

Beddoe, L. (2015). Making a moral panic - "Feral families", family violence and welfare reforms in New Zealand: Doing the work of the state? In V. E. Cree (Ed.), Moral panics in theory and practice: Gender and family (pp. 31-42). Bristol, UK: Policy Press. 
Beddoe, L. (2017). Managing identity in a host setting: School social workers' strategies for better interprofessional work in New Zealand schools. Qualitative Social Work. doi:10.1177/1473325017747961

Beddoe, L., \& De Haan, I. (2018). Addressing concerns about child maltreatment in schools: A brief research report on social work involvement in reporting processes. Aotearoa New Zealand Social Work, 30(1), pp.

Belgrave, M. (2000). Evaluation of the Social Workers in Schools pilot programme. Wellington, New Zealand: Child, Youth \& Family.

Belgrave, M., Jakob-Hoff, M., Milne, S., Selby, R., Asiasiga, L., Mataira, P., ... Thorpe, A. (2002). Social workers in schools: Expansion evaluation. Wellington, New Zealand: Ministry of Social Development.

Buckley, H., \& McGarry, K. (2011). Child protection in primary schools: A contradiction in terms of a potential opportunity? Irish Educational Studies, 20(1), 113-128.

Bye, L., Shepard, M., Partridge, J., \& Alvarez, M. (2009). School social work outcomes: Perspectives of school social workers and school administrators. Children \& Schools, 31(2), 97-108.

Corbin, J. N. (2005). Increasing opportunities for school social work practice resulting from comprehensive school reform. Children \& Schools, 27(4), 239-246.

Daniel, B., Taylor, J., \& Scott, J. (2010). Recognition of neglect and early response: Overview of a systematic review of the literature. Child and Family Social Work, 15, 248-257.

Dupper, D.R. (2003). School social work: Skills and interventions for effective practice. New Jersey, United States: John Wiley \& Sons.

Garrett, K. J. (2006). Making the case for school social work. Children \& Schools, 28(2), 115-121.

Goren, S.G. (2006). The wonderland of social work in the schools, or how Alice learned to cope. In R. Constable, C.R. Massat, S. McDonald \& J.P. Flynn (Eds.), School social work: Practice, Policy and Research (6th ed), (5866). Chicago, Illinois, United States: Lyceum Books.

Hollis-English, A., \& Selby, R. (2014). Social work in schools in New Zealand: Indigenous social work practice. Journal of Indigenous Social Development, 3(2), 1-10.

Isaksson, C., \& Sjöström, S. (2016). Looking for "social work" in school social work. European Journal of Social Work, 1-12. Doi:10.1080/13691457.2016.1188775

Jarolmen, J. (2014). School social work: A direct practice guide. Thousand Oaks, CA: Sage Publications.

Kelly, M. S., Frey, A. J., \& Anderson-Butcher, D. (2010). School social work practice: Future directions based on present conditions. Children \& Schools, 43(4), 195-199.

Klika, J. B., \& Herrenkohl, T. I. (2013). A review of developmental research on resilience in maltreated children. Trauma, Violence, \& Abuse, 14(3), 222-234.

Kurtz, P. D., \& Barth, R. P. (1989). Parent involvement: Cornerstone of school social work practice. Social Work, 34(5), 407-413.

Levi, B. H., Crowell, K., Walsh, K., \& Dellasega, C. (2015). How childcare providers interpret "reasonable suspicion" of child abuse. Child \& Youth Care Forum, 44(6), 875-891. doi:10.1007/s10566-015-9302-5

Levi, B. H., \& Portwood, S. G. (2011). Reasonable suspicion of child abuse: Finding a common language. The Journal of Law, Medicine \& Ethics, 39(1), 62-69. doi:10.1111/ j.1748-720X.2011.00550.x

McGarry K., \& Buckley, H. (2013). Lessons on child protection: A survey of newly qualified primary-level teachers in Ireland. Child Abuse Review, 22, 80-92.

McKee, B. E., \& Dillenburger, K. (2002). Effectiveness of child protection training for pre-service early childhood educators. International Journal of Educational Research, 53, 348-359.

Minnich, K. J. (2014). A phenomenological study of workplace empowerment and self-efficacy of school social workers. (Unpublished doctoral dissertation). Walden University, Minneapolis, United States.

Ministry of Social Development (n.d. a). Social workers in schools. Retrieved from: http://www.msd.govt.nz/aboutmsd-and-our-work/publications-resources/evaluation/ social-workers-in-schools/

Ministry of Social Development (n.d. b). Youth workers and social workers in schools (SWiS, MASSiSS and YWiSS). Retrieved from: https://www.familyservices.govt.nz/ about-programmes/the-swis-service/index.html

Nagy Hesse-Biber, S., \& Leavy, P. (Eds.). (2004). Approaches to qualitative research: $A$ reader on theory and practice. New York, NY: Oxford University Press.

O'Toole, R., Webster, S. W., O'Toole, A. W., \& Lucal, B. (1999). Teachers' recognition and reporting of child abuse: A factorial survey. Child Abuse \& Neglect, 23(11), 1083-1101.

Pawlak, E. J., \& Cousins, L. (2006). School social work: Organizational perspectives. In R. Constable, C. R. Massat, S. McDonald \& J. P. Flynn (Eds.), School social work: Practice, policy and research (6th ed, pp. 225-239). Chicago, IL: Lyceum Books.

Peckover, C. A., Vasquez, M. L., Van Housen, S. L. Saunders, J. A., \& Allen, L. (2012). Preparing school social work for the future: An update of school social workers' tasks in lowa. Children \& Schools, 35(1), 9-17.

Phillippo, K. L., \& Blosser, A. (2013). Specialty practice or interstitial practice? A reconsideration of school social work's past and present. Children \& Schools, 35(1), 19-31.

Poppy, Alexia A. (2012). The role of a school social worker from an administrator's perspective. (Unpublished Master of Social Work clinical research paper). St Catherine University/University of St. Thomas, Minnesota, United States.

Rodriguez, C. (2002). Professionals' attitudes and accuracy on child abuse reporting decisions in New Zealand. Journal of Interpersonal Violence, 17(3), 320-342.

Romano, E., Babchishin, L., Marquis, R., \& Fréchette, S. (2015). Childhood maltreatment and educational outcomes. Trauma, Violence, \& Abuse, 16(4), 418-437.

Scannapieco, M. (2006). Building effective alliances with child protective services and other child welfare agencies. In C. Franklin, M. B. Harris, \& P. Allen-Meares (Eds.), The school services sourcebook: A guide for school-based professionals (pp. 383-388). New York, NY: Oxford University Press.

Schols, M. W., de Ruiter, C., \& Ory, F. G. (2013). How do public child healthcare professionals and primary school teachers identify and handle child abuse cases? A qualitative study. BMC Public Health, 13, 807-821. 
Selby, R., English, A., \& Bell, H. (2011). Social workers in schools: A New Zealand Māori experience. Ōtaki, Aotearoa New Zealand: Te Wānanga o Raukawa.

Sherman, M. C. (2016). The school social worker:

A marginalized commodity within the school ecosystem. Children \& Schools, 38(3), 147-151.

Staudt, M., \& Kemp Powell, K. (1996). Serving children and adolescents in the school: Can social work meet the challenge? Child and Adolescent Social Work Journal, 13(5), 433-446.

Ungar, M. (2002). A deeper, more social ecological social work practice. The Social Service Review, 76(3), 480-497.

Walsh, K. M., Mathews, B., Rassafiani, M., Farrell, A., \& Butler, D. (2012). Understanding teachers' reporting of child sexual abuse: Measurement methods matter. Children and Youth Services Review, 34(9), 1937-1946.

Warner, J. (2015). The emotional politics of social work and child protection. Bristol, UK: Policy Press.

Webb, R., \& Vulliamy, G. (2001). The primary teacher's role in child protection. British Educational Research Journal, 27(1), 59-77.

Webster, S. W., O'Toole, R., O'Toole, A. W., \& Lucal, B. (2005). Overreporting and underreporting of child abuse: Teachers' use of professional discretion. Child Abuse and Neglect, 29, 1281-1296.

Whittlesey-Jerome, W. (2013). Results of the 2010 statewide New Mexico school social work survey: Implications for evaluating the effectiveness of school social work. School Social Work, 37(2), 76-87.

\section{Endnotes}

To be in difficulty, perplexed, troubled. Māori Dictionary (http://maoridictionary.co.nz/). 